\title{
Determiners and (Un)certainty
}

\author{
Jacques Jayez and Lucia M. Tovena \\ ENS-LSH, Lyon University of Lille
}

\section{Introduction}

As noted by Haspelmath (1997), determiners and pronouns sensitive to "knowledge of the speaker" exist in different languages. Examples are the -to series in Russian, some and a certain (see Farkas, this volume), and irgendein in German (Kratzer 2001). This paper examines the epistemic properties of a set of French determiners, i.e. un $\mathrm{N}$ quelconque (some), quelque (some) and un certain (a certain). They appear to be in complementary distribution due to their symmetric sensitivities to the epistemic status of the NP referent. We aim to contribute to a better understanding of their sensitivity by relating it to the well-known problem of "identifiability" in epistemic logic.

The structure of the paper is as follows. In section 2, we present the basic data on un $\mathrm{N}$ quelconque and introduce the notion of identification needed to spell out the conditions of non-identification required by this expression. We discuss differences and points of contact between ignorance and indifference to the identity of the referent, which brings us to contrast the items under examination with free choice items (FCIs). Then, we take into consideration the fact that the epistemic agent is not necessarily the speaker, but several perspectives may be taken up. In section 3, we look at un certain which, on the contrary, seems to require the referent to be identified. We show that, beside the speaker's knowledge of the referent, there must be another independent identification. Finally, in section 4, we look at the interaction of these determiners with abstract mass nouns.

\section{Un quelconque}

French has two determiners that express ignorance about the referent, i.e. quelque and un quelconque. Quelque is formal and old fashioned in modern French and has in effect been replaced by un quelconque. Accordingly, we will focus on the latter. However we will consider the combination quelque with abstract mass, nouns at the end of the paper. Un quelconque shows up in the two constructions un $\overline{\mathrm{N}}$ quelconque (UQ1) and un quelconque $\overline{\mathrm{N}}$ (UQ2). We consider UQ2 to be a variant of UQ1 where the indiference value is "stronger", in a sense to be made clear at the end of section 2.3. We will focus on UQ1 in the rest of the paper.

\subsection{Basic properties}

In this section, we review the properties of un $\mathrm{N}$ quelconque (UQ1). This phrase 
is fine in "modal" contexts, that is, sentences expressing probability (1a,b), possibility (1c), obligation (1d), permission (1e), command/suggestion (1f), or habitual sentences $(1 \mathrm{~g})$.

(1) a. Marie a probablement loué une voiture quelconque 'Mary probably rented some car'

b. Marie a dû louer une voiture quelconque 'Mary must have rented some car or other'

c. Marie a pu louer une voiture quelconque 'Mary was able to rent some car'

d. Marie doit louer une voiture quelconque 'Mary has to rent some sort of car'

e. Marie a le droit de louer une voiture quelconque 'Mary is allowed to rent some sort of car'

f. Loue une voiture quelconque 'Rent some car or other'

g. Quand elle était en vacances, Marie louait habituellement une voiture quelconque

'On holiday, Mary usually rented some car'

In episodic non-modal sentences, UQ1 is appropriate when the sentence is compatible with the assumption that the speaker cannot identify the reference of UQ1.

(2b) is anomalous, because, under normal circumstances, it implies that the speaker is able to identify the referent.

(2) a. Susanne a épousé un copain de fac quelconque, que je ne connais pas 'Susan married some university friend, whom I don't know'

b. J'ai rencontré ?? un ami quelconque 'I met some friend'

UQ1 is not always appropriate with non-specific NPs.

(3) a. Pour mon anniversaire, je voudrais une lampe de bureau ?? quelconque 'For my birthday, I would like some desk lamp'

b. Il me faut un livre quelconque sur les types récursifs 'I need some book on recursive types'

In generic sentences, UQ1 is not appropriate when it occurs as restriction of a generic operator. In (4c), UQ1 is in the scope.

(4) a. Un animal doit être soigneusement nourri 'An animal must be fed with care'

b. Un animal ?? quelconque doit être soigneusement nourri

'Some animal must be fed with care'

c. Un chat doit avoir un jouet quelconque

'A cat must have some sort of a toy' 
UQ1 is also appropriate in downward-entailing contexts where it can function as a minimiser/Negative Polarity Item, exactly as un. We will leave aside this particular function, as it is the likely product of un's contribution.

a. Marie n'a pas rencontré un étudiant 'Mary did not meet any student'

b. Marie n'a pas rencontré un étudiant quelconque

'Mary did not meet any student'

Note that, like un and $a$ in English, UQ1 may "escape" negation in referential readings. In (6), for instance, the intended interpretation is that there is some particular code that Mary did not type in.

(6) Marie n'a pas dû rentrer un code quelconque, ce qui a suspendu le système 'There must be some code Mary failed to type in, which stalled the system'

Examples (1) and (2) suggest the following constraint on UQ1.

Non-Identification A sentence with UQ1 is not felicitous when it implies that the speaker is able to identify the referent of UQ1.

The next section spells out the notion of identification. Examples (3) and (4) cannot be reduced to the simple constraint in (7) and will be dealt with in section 2.3.

\subsection{Identification}

The notion of identification concerns the epistemic status of a cognitive agent with respect to a set of individuals. An agent $a$ identifies an individual $d \in D$ if and only if $a$ is able to discriminate between $d$ and the other members of $D$. Identification is usually associated with "descriptions", a cover term for aggregates (Dekker, 1998), individuation schemes (Gerbrandy 1998, 2000) and counterparts (Geach 1967, Lewis 1968, van Rooy 1997, Zeevat 1997, Aloni 2001, etc.).

A Description $\Delta$ is a bundle of properties. An individual $a$ is identified through $\Delta$ whenever it is the only individual which satisfies $\Delta$. Identification is essentially opposed to intentional identity in the sense of (Geach 1967). More formally, the basic notion is that of type in model theory, that is, a set of formulas which characterizes all the ( $n$-tuples of) individuals which satisfy them. Following Hodges (1997, p. 39), we have the definition in (8).

(8) Type Let $T$ be a theory in the language $L$. An $n$-type of $T \Phi\left(x_{1} \ldots x_{n}\right)$ for $n$ finite is any subset of $T$ in the free variables $x_{1} \ldots x_{n}$. $\vec{x}$ abbreviates the sequence $x_{1} \ldots x_{n}$.

The denotation of an $n$-type w.r.t. some model $\mathcal{M}$ is the set of sequences $\left\langle a_{1}, \ldots, a_{n}\right\rangle$ which satisfy the type.

(9) Type denotation The denotation of $\Phi(\vec{x})$ w.r.t. $\mathcal{M}, \llbracket \Phi(\vec{x}) \rrbracket_{\mathcal{M}}$ is the set $\left\{\left\langle a_{1}, \ldots, a_{n}\right\rangle \mid a_{1} \ldots a_{n} \in D_{\mathcal{M}} \& \mathcal{M} \models \Phi(\vec{x})[\vec{x} \leftarrow \vec{a}]\right\}$. 
Note that when $n=0$, an $n$-type $\Phi$ is a set of closed formulas. $\llbracket \Phi \rrbracket$ is then the set of finite sequences of elements of $D_{\mathcal{M}}$ or the empty set.

An $n$-type $\Phi$ is proper iff (i) it is non-empty and (ii) $n>0$.

Epistemic individuation amounts to identification through types in an epistemic setting, i.e. a situation where an agent contemplates several "alternatives", or mutually incompatible models of a language. Let us assume, for simplicity, that (i) we work in a "full" language (each individual of the domain has a name in the language: $a \leftrightarrow c_{a}$ ) and that (ii) constant symbols are rigid (they receive a unique interpretation in the domain).

(11) Information state An information state (i.s.) $s=(\mathbb{M}, D)$ is a set of mutually incompatible models over a common non-empty domain $D$. An agent $a$ knows that $\phi$ if she entertains an i.s. $s$ in which $\mathcal{M}_{i} \models \phi$ for every $\mathcal{M}_{i} \in \mathbb{M}$. Let $\Phi_{K_{a}}$ denote the set of formulas $\phi$ such that $a$ knows that $\phi$.

An agent $a$ knows which entities satisfy the proper $n$-type $\Psi$ whenever $\Psi$ gets the same denotation in every model of $\mathbb{M}$.

(12) Knowing which a knows which entities satisfy the proper $n$-type $\Psi$ in $s=(\mathbb{M}, D)$ iff for each sequence $\left\langle c_{1} \ldots c_{n}\right\rangle$ and every $\phi\left(x_{1} \ldots x_{m}\right) \in \Psi$, either $\phi[\vec{x} \leftarrow \vec{c}] \in \Phi_{K_{a}}$ or $\neg \phi[\vec{x} \leftarrow \vec{c}] \in \Phi_{K_{a}}$.

The formal counterpart of (7) is (13).

(13) UQ1 A sentence with a tripartite structure [UQ1] $[\overline{\mathrm{N}}][P]$ is appropriate only under an interpretation (i.s.) $s$ such that the speaker does not know which entity satisfies the proper 1-type $\{\overline{\mathbf{N}}(x) \& P(x)\}$ in $s$.

We account for examples (1)-(4) as follows. First, for the modal nonspecific examples (1a-f), given an i.s. $s=(\mathbb{M}, D)$, and a modal necessity or possibility operator $\bigcirc$, the logical form is:

\section{$\bigcirc[\exists x(x$ is a car \& Mary rented $x)]$.}

The type is not necessarily rigid across the different models of the information space. Mary may have had the possibility, the permission, the obligation, etc., to rent any appropriate car, not a particular one. Adopting a standard quantificational view on the representation of habitual sentences (de Swart 1991), we posit (1g') as the logical form of (1g).

(1) g'. $\mathrm{HAB}_{s}$ [Mary is on vacations in $s \& s$ is past] $[\exists x$ ( $x$ is a car in $s$ \& Mary rents $x$ in $s$ )]

Second, it is the specific reading that is preferred for (2a); so, Susan married a particular university friend, but his identity is unknown to the speaker. In practice, this means that the proper 1-type ( $x$ is a university friend \& Susan married $x$ ) is not satisfied by the same individual in every alternative of $\mathbb{M}$. In contrast, the preferred interpretation of $(2 b)$ is one where the agent has perceptually identified the friend. 
We introduce a rigid predicate $P E R C_{s p}$ that applies to the object perceptually identified by the speaker in the situation. Since every model in $\mathbb{M}$ supports $\exists x$ (I met $x$ $\& x$ is a friend \& $P E R C P_{s p}(x)$ ), we see that the proper 1-type (I met $x \& x$ is a friend \& $\left.P E R C P_{s p}(x)\right)$ is satisfied by the same individual in every alternative of $\mathbb{M}$.

\subsection{Non-identification and indifference}

Non-specific contexts like (3) raise a more difficult problem. Consider (3a) and suppose that it is issued in a situation where I have no precise idea of the kind of desk lamp I need. In this case, the speaker is unable to identify the lamp. So, why is UQ1 anomalous? A similar observation holds for progressive sentences. In modal/inferential approaches to the progressive (see Dowty 1979, Landman 1992, Zucchi 1999 among many others), a sentence like (14) has an interpretation in which I may not have a very precise idea of the paper I am currently writing. So several different articles might result from my current activity. Yet, UQ1 is not felicitous.
a. Je suis en train d'écrire un article
'I am writing a paper'
b. Je suis en train d'écrire un article ??quelconque 'I am writing some paper or other'

In fact, the property of UQ1 responsible for these anomalies manifests itself more covertly in (2a), where the speaker signals that she has no means to identify the person whom Susan married. Since the relative clause ('whom I don't know') entails the same information, one may wonder whether UQ1 really adds something to the meaning. Intuitively, (2a) conveys the impression that the speaker is unconcerned with Mary's marriage. Van de Velde (2000) proposes that quelque, similar to UQ1 in many respects as noted above, signals that the identity of the referent is irrelevant. This seems to be the case in (2a), which has a 'I don't care' flavour. Farkas (this volume) and von Fintel (2000) mention similar possibilities for some and whatever. We will speake of the indifference value of UQ1. This value is not automatically triggered by UQ1. In Gricean terms, it is cancellable. For instance, the identity of the referent is relevant in $(15 \mathrm{a}, \mathrm{b})$.

(15) a. Marie a dû être mise au courant du projet par un employé quelconque, et il faudrait savoir qui

'Mary must have learnt about the project from some employee and we need to know who it is'

b. La victime a forcément entendu un bruit quelconque, mais je me demande bien quoi

'Surely, the victim heard some noise, but I really wonder what'

One might speculate that, being (i) connected with the presence of a particular determiner (UQ1) and (ii) cancellable, the indifference value is a generalized conver- 
sational implicature (GCI) in the sense of Grice (1967). However, one should say why the attempted cancellation fails in (2c), which sounds somewhat incoherent. As pointed out by Geurts (1999:19-23) in particular, cancellation of implicatures is not analogous to the phenomenon of presupposition projection. For instance, in (2d), the existence of Susan's husband is suspended by the si-clause. Implicatures result from the contextual interpretation of a sentence as a whole and cannot be easily defeated by additional information. ${ }^{1}$

(2) c. Susanne a épousé un copain de fac quelconque, ?? que j'aimerais bien connaître

'Susan married some university friend, whom I'd like to know'

d. Le mari de Susanne doit être heureux, si elle est mariée

'Susan's husband must be happy, if she is married'

These variations suggest that UQ1 has a more complex profile than what (13) captures. (13) is like an antilicensing condition stating that UQ1 is not licensed in environments where the preferred interpretation violates non-identification. So, UQ1 communicates two implicatures, expressed in (16).

(16) A sentence with a tripartite structure [UQ1] [N] [P]

(i) conventionally implicates (literal meaning) that the speaker is in an i.s. $s$ such that she ignores which entity satisfies the proper 1-type $\{\overline{\mathrm{N}}(x) \& P(x)\}$ in $s$,

(ii) communicates, as a GCI, the idea that the speaker is unconcerned with the identity of the entity satisfying the proper 1-type $\{\overline{\mathrm{N}}(x) \& P(x)\}$ in $s$.

As with every GCI, when the context makes it clear that the literal meaning is the preferred interpretive option, the GCI can be suspended. (16) accounts for the variability observed in (3) and (15). In (3a), the speaker is unconcerned with the identity of the lamp, but this clashes with the indication 'for my birthday', which implicates that she expects or hopes to like it. In ( $3 b)$, the speaker might be unconcerned with the identity of the book as far as it contains standard material on recursive types. In (15), the GCI is defeated by the abductive interpretation: the speaker stresses the fact that she was only able to derive an incomplete conclusion, and that a crucial piece of information is lacking.

A generic sentence like (4b) raises a more difficult problem. Its logical form is (4b'), assuming a GEN operator of the type described in (Carlson \& Pelletier 1995).

(4) b'. GEN ${ }_{s}\left[\left[\mathrm{UQ} 1_{x}\right][x\right.$ is a cat] [ $x$ exists in $\left.s]\right]$ [one must feed $x$ with care in $s$ ]

(4b') says that, in situations $s$ that pertain to the evaluation of the generic sentence, when there are "some" cats in $s$, they must be fed with care. This logical form does not violate constraint (13), since it is possible for the speaker to ignore which cats exist in the relevant situations. The GCI is clearly inappropriate since the speaker does not have to be concerned or unconcerned with the identity of cats in possible situations. The literal meaning does not offer an escape hatch either, because 
generic quantification via GEN involves ignorance about individual referents. So, it is unlikely that the speaker wants to emphasize this ignorance independently, through the use of UQ1. Note that this is a general property of generic sentences: since they conventionally imply that the speaker is not referring to any specific entity, the literal meaning (conventional implicature) of UQ1 cannot be used to redeem the combination of UQ1 with genericity. This means that, in such cases, we have to find some motivation for the GCI of UQ1.

As expected, generic sentences can host UQ1 when the GCI can be perceived as adding relevant information. This is typically the case in possibility sentences like the following ones.

a. On peut se réincarner en un animal quelconque 'One can be reincarnated as any animal'

b. Avec ce nouveau logiciel, on peut scanner un texte quelconque ${ }^{2}$ 'With this new software, one can scan any text'

The variant of (17a) without UQ1 (On peut se réincarner en un animal 'One can be reincarnated as an animal') does not imply that any animal is an admissible host for reincarnation. By using UQ1, the speaker indicates that she is indifferent to which animal is considered. There are (at least) two ways in which this indifference can be interpreted. First, as in the previous case, the indifference may be affective (the speaker is simply unconcerned), but it is an implausible situation. Asserting that a property holds of the members of a class and implying that one is unconcerned with which member is considered, seem two totally unconnected attitudes. So, the affective scenario fails. Second, the speaker might consider that the truth of her judgment does not depend on the identity of the animals. She is unconcerned with the information because her contribution to the discourse does not depend on it. In such cases, UQ1 carries the same meaning as a free-choice item like n'importe quel or any (Jayez \& Tovena 2001).

One might object that this free-choice reading should apply to generics like (4b). A widening/strengthening effect à la Kadmon and Landman (1993) might produce the reading 'absolutely every animal must be fed with care'. But, clearly, this is not the case. To see why, we have to take into account the peculiar semantic structure of generics with indefinite singular subjects (IS-generics). Greenberg (this volume) recently proposed that IS-generics assert a connection between properties in virtue of a linking property. For instance, (4a) expresses a connection between the property of being an animal and the property of being fed with care in virtue of a third property (presumably that of being sensitive to the quality of food). Following Greenberg $^{3}$, (4a) would be represented as (4a'), where $w$ is the world of evaluation.

a'. $\exists \mathcal{P} \forall w^{\prime}$ (IF $x$ is an animal in $w^{\prime} \& x$ satisfies $\mathcal{P}$ in $w^{\prime} \& \mathcal{P}$ is associated with the property of being an animal in $w$, THEN $\forall x, s$ ( $s$ is in $w^{\prime} \& x$ is a cat in $s \Rightarrow x$ must be fed with care in $s$ ))

A property is associated with the restriction in virtue of epistemic, deontic, legal, or stereotypical knowledge. The idea behind Greenberg's analysis is that there is 
a mediating property $(\mathcal{P})$ between the restriction and the scope of the IS-generic judgment. Obviously, this does not entail that every entity denoted by the subject of the generic sentence possesses the mediating property, since this property is simply associated (not entailed).

Using n'importe quel or any, as in N'importe quel animal doit être nourri avec soin 'Any animal must be fed with care' signals that we can consider mediating properties which are weaker than those associated with the restriction, potentially including cases otherwise excluded. For instance, if the initial mediating property denotes the set of stereotypical animals, saying that 'any animal must be fed with care' may convey the idea that even non-stereotypical animals must be fed with care. This is a simple case of what Kadmon and Landman call "widening". ${ }^{4}$ UQ1 does not imply that the mediating property is extended. It only implies that the speaker is indifferent to the identity of the individuals which satisfy the generic. In contrast, it says nothing about the fact that these individuals are stereotypical or not. In many contexts, the irrelevance of individuals for the speaker can be interpreted as motivated by the belief that the generic has no or few exceptions, whence the impression that UQ1 and n'importe quel 'any' do exactly the same job. In fact they don't: the "absence" of exception is a particularized conversational implicature in the case of UQ1, whereas it is a conventional implicature on the case of n'importe quel. To ease a comparison of their semantic profiles, in (18) we cast the contribution of $n$ 'importe quel in Greenberg's format.

(18) An IS-generic sentence of form [N'IMPORTE QUEL] $[R][S]$ conventionally implicates that the mediating property $P$ is a superset of the property associated with the restriction $R$.

So, interpreting UQ1 in an IS-generic structure does not produce a natural reading because the affective scenario is useless and the epistemic scenario is not available. Generic when or if-clauses like (19) demonstrate the importance of the GCI of UQ1. The scope property (the obligation of feeding with care) is not predicated directly of animals but of animals in particular situations or of individual-situation pairs. So, the logical form of (19) is (19'). As the generic operator bears on situations, (19') leaves open the possibility that, in the situations considered for evaluating the generic, the type of the animal is not just any type. By implying that this is indeed the case, UQ1 retains a certain informativity, in the epistemic scenario.

Quand/Si on a un animal quelconque, il faut le nourrir avec soin , 'When/If one has some animal, one must feed it with care'

(19) $\left[\mathrm{GEN}_{s}\right.$ ] [one has an animal in $s$ ] [one must feed it with care in $s$ ]

Summarizing, we have proposed that the indifference value of UQ1 is a GCI, motivated by (at least) two different scenarios which interact in certain ways with various semantic structures. Note that, if one follows von Fintel (2000: def. 21), the indifference value of whatever is nearer to free-choiceness than to the lack of concern suggested by UQ1

Next, we have to add something to account for contrasts such as (20), that 
suggest that UQ1 is intrinsically derogatory or indiscriminative, like just any (Horn 2000), and conflicts with laudatory terms like génie 'genius'.

a. Pour résoudre ce problème il faudrait un génie (?? quelconque) 'To solve this problem we need a genius (some genius)'

b. Un imbécile (quelconque) a dû laisser la lumière allumée 'An (Some) idiot must have left the lights on'

(20a) is paralleled by He is not? ${ }^{\text {? }}$ just any genius, but this is not the case in examples like (21). Thus, instead of associating with UQ1 a derogatory value, we propose that the semantic category of the $\overline{\mathrm{N}}$ must not presuppose that the denoted entities have particular abilities or (positive or negative) qualities. This corresponds in part to Lyon's idea (1977) that in pairs like small vs big, only the latter adjective refers to an actual property. Big things "have bigness", they don't "lack smallness". Small things don't "have smallness", they "lack bigness".

Si tu as un problème quelconque avec ta machine, appelle-moi

'If you have any problem with your computer, call me'

The distinction between imbécile and génie in (20) would match the fact that one does not need any special ability to be an idiot. Similar contrasts exist for petit 'small' vs grand 'big' or laid 'ugly' vs beau 'beautiful'. So, the constraint we put on UQ1 is that the $\overline{\mathrm{N}}$ must not denote a class of entities which are unfrequent or exceptional in any respect. Since this is not a cancellable aspect of the determiner, we consider it as a conventional implicature in its core meaning. The presence of this negative (antilicensing) condition accounts for the fact that UQ1 and the adjective quelconque are only partly similar. Quelconque as an adjective is derogatory and denotes things which are nondescript: des vêtements quelconques 'nondescript clothes', Je suis un cuisinier quelconque 'I am a poor cook'. So, it is not felicitous in contexts where, clearly, the denoted entity can be any entity in the class.

Si tu as un problème ?? quelconque-ADJ, délicat ou pas, appelle-moi 'If you have a routine problem, tricky or not, call me'

\subsection{The problem of perspectives}

Up to this point, we have been assuming that the speaker is the only epistemic agent. But this is not always the case. For instance (23a) is odd because, in its preferred interpretation, the event is presented under the perspective of the agent, who is not the speaker and who is supposed to know which car she sees. This perspective is probably facilitated or imposed by the passé simple ('simple past'), which stresses the distance from the utterance time (Vetters, 1996:155).

a. Marie se pencha par la fenêtre et aperçut une voiture ?? quelconque, que je ne pouvais pas voir

'Mary leant out of the window and saw some car, which I couldn't see' 
b. Marie se pencha par la fenêtre et dut voir une voiture quelconque, dont j'entendis le moteur

'Mary leant out of the window and probably saw some car, of which I heard the engine'

Perspectives (viewpoints, focal points, etc.) are well-known in literary studies (Booth 1983, Genette 1983, Achard-Bayle 2001, etc.). Formally, they are usually represented by means of epistemic logics (Hintikka 1962, Fagin et al. 1995, Gerbrandy 1998). The standard translation of the epistemic situation in (23a) is as in (23a'), where $K$ is a knowledge operator and $s$ is the speaker.

$$
\mathrm{a}^{\prime} . K_{s} \exists ! x\left(K_{\text {Mary }} x \text { is a car \&'Mary saw } x\right)
$$

(23a') is true at $w$ if and only if $\exists ! x\left(K_{\text {Mary }} x\right.$ is a car \& Mary saw $\left.x\right)$ is true at every world $w^{\prime} K_{s}$-accessible from $w$. This entails, in turn, that for each such $w^{\prime}$, there is a unique individual, say $a_{w^{\prime}}$, that satisfies the proper 1-type ( $x$ is a car \& Mary saw $x)$ in $\mathbb{M}=\left\{w^{\prime \prime}: w^{\prime \prime}\right.$ is $K_{\text {Mary }}$-accessible from $\left.w^{\prime}\right\}$. As expected, the speaker $s$ does not know which car Mary saw. Adopting the perspective of Mary means to consider any set of worlds $K_{\text {Mary }}$-accessible from some $w^{\prime}$. More generally, we define perspectives as localizations in possibilities in the sense of Gerbrandy (1998).

(24) Let $\mathcal{L}$ be a (full) language and $\mathcal{A}$ a finite set of agents. A possibility over $\mathcal{L}$ and $\mathcal{A}$ is a function $\pi$ such that:

1. $\pi(\mathcal{L})$ is a model of $\mathcal{L}$, and

2. $\pi(a)$, for every $a \in \mathcal{A}$ is a set of possibilities called an information state (i.s.).

I.s. are noted $\sigma, \sigma_{i}$, etc. Truth is defined as expected. A formula $\phi$ is true at a possibility $\pi, \pi \models \phi$ in symbols, if and only if $\pi(\mathcal{L}) \models \phi$. It is true at an i.s. $\sigma$ if and only if, for each $\pi \in \sigma, \pi \models \phi$. In the simple model adopted here, a perspective is just a set of i.s. nodes in the tree associated with a possibility. E.g., the perspective assigned to Mary by the speaker $s$ is the set of i.s. Mary-accessible from each $a-$ accessible possibility, i.e. the set $\left\{\sigma: \pi_{i}\right.$ (Mary) $=\sigma$ for some $\left.p i_{i} \in \pi(s)\right\}$. In the general case, we

(25) Let $\pi$ be a possibility. An information path (i.p.) in $\pi$ is any finite sequence of the form $\left\langle x_{1}, \pi_{1}, x_{2}, \pi_{2} \ldots, x_{n}, \sigma\right\rangle$ such that the $x_{i}$ 's are in $\mathcal{A}, \pi_{1} \in \pi\left(x_{1}\right)$, for each $x_{i}(1<i<n): \pi_{i} \in \pi_{i-1}\left(x_{i}\right)$ and $\sigma=\pi_{n-1}\left(x_{n}\right)$.

For a given sequence of agents $\left\langle x_{1} \ldots x_{n}\right\rangle$, the perspective at this sequence is the set of i.s. that form the endpoints of the i.p. using this sequence.

(26) Let $\omega=\left\langle x_{1} \ldots x_{n}\right\rangle$ be a finite sequence of agents. The perspective at $\omega$ is the set of i.s. defined by $\left\{\sigma_{i}\right.$ : there is an i.p. of the form $\left.\left\langle x_{1}, \pi_{1} \ldots x_{n}, \sigma_{i}\right\rangle\right\}$ in the total possibility $\pi$.

The next step is to redefine 'knowing which' for possibilities and perspectives. 
(27) Knowing which under perspectives Let $\omega=\left\langle x_{1} \ldots a\right\rangle$ be a sequence of agents and $\Pi$ the perspective at $\omega . a$ knows which entities satisfy the proper $n$-type $\Psi$ under $\Pi$ iff $a$ knows which entities satisfy the type in each member of $\Pi$.

(27) amounts to saying that, no matter which i.s. is considered at the endpoint of a given i.p., the agent knows which entities satisfy the type when she is in this i.s. Adopting the perspective "of" an agent consists, in this type of representation, in evaluating a sentence at the perspective which describes the way in which a sequence of agents sees the information that this agent has. For instance, adopting the perspective of Mary in (23) is not seeing the world "as Mary sees it" but rather as the speaker believes that Mary sees it. The relevant perspective is then the perspective at $\langle s$, Mary $\rangle$. More generally, we can replace the notion of information state as a set of models by that of perspectives at a sequence of agents. Definition (13) must then be slightly modified, as in (28).

(28) A sentence with a tripartite structure [UQ1] [N] [P] is appropriate only under a perspective $\Pi$ at $\omega$ such that the last agent of $\omega$ does not know which entity satisfies the proper 1-type $\{\overline{\mathrm{N}}(x) \& P(x)\}$ under $\Pi$.

\section{Un certain}

Certain forms three determiners in French: un certain, certain, and certains. ${ }^{5}$ Assessing their interrelation, diachronically and semantically, is a complex task that exceeds the scope of this paper (see Allaert 1999 for some observations). We simply note that (i) certain, like quelque, is somewhat formal and old fashioned and (ii) data suggest that certains is not just the plural of un certain. For instance (29b) is less natural than (29a) in isolation. In what follows we focus on un certain (UC).
a. Certains collègues ont accepté de relire mon article 'Certain colleagues accepted to read over my paper'
b. \#Un certain collègue a accepté de relire mon article 'A certain colleague accepted to read over my paper'.

\subsection{Basic facts}

As noted by Van de Velde (2000), UC is, to some extent, symmetric to quelque. This observation extends to UQ1. By and large, UC is possible with episodic nonmodal sentences, not always felicitous in modal sentences and possible with abstract nouns.

(30) a. J'ai rencontré un certain diplomate dont on m'avait parlé 'I met a certain diplomat whom I had heard of'

b. Jean a dû avoir \# un certain problème 
'John must have had a certain problem'

c. Jean a fait preuve d'une certaine intelligence

'John showed a certain amount of intelligence'

These and similar data suggest that, in contrast with UQ1 and quelque, UC requires the referent to be already known. This squares well with its compatibility with proper nouns (un certain Jean 'a certain John') which have an intrinsic identification potential according to some analyses (Geurts 1997). However, calibrating this 'previous acquaintance' is not easy. It is not necessarily knowledge of the speaker (31a) and the knowledge criterion does not apply to certain collocations (31b). In the next section, we consider two proposals for analyzing UC in French and a certain in English.
a. Jean a mentionné un certain diplomate 'John mentioned a certain diplomat'
b. Jean a dû se douter du complot à partir d'un certain moment 'John must have suspected the conspiracy at some stage'

\subsection{Distinction and specificity}

A classical reference on certains in French is (Gondret 1976). This author proposes that certains must refer to a set whose members can be 'distinguished', that is, retain their individuality. For instance, Gondret explains the impossibility of (32) by pointing out that the kilometers which are referred to are not individualized.

$$
\begin{aligned}
& \text { Il habite à *certains kilomètres } \\
& \text { 'He lives *certain kilometers from here' }
\end{aligned}
$$

Allaert (1999:145) takes up this intuition and summarizes the behavior of UC with concrete nouns by the slogan un certain $N=$ un $N$ distinct parmi l'ensemble des $N$ ('A certain $\mathrm{N}=$ a distinguished $\mathrm{N}$-thing within the set of $\mathrm{N}$-things'). While the intuition is correct, the idea of distinction remains extremely vague as a criterion. Suppose, for instance, that indefinites are represented by means of choice functions, as proposed in many recent contributions on determination (see Reinhart 1992, 1997 for two seminal papers). Let us consider (29c), a variant of (29b) containing the standard indefinite un ' $a$ ', and its possible representation in (29c'), $f$ being a choice function variable.

$$
\begin{aligned}
& \text { c. Un collègue a accepté de relire mon article } \\
& \text { 'A colleague accepted to read over my paper' } \\
& \text { c'. } f(\text { COLLEAGUE) accepted to read over my paper }
\end{aligned}
$$

If un certain collègue in (29b) involves 'distinction', the choice of the choice function that can be the value of $f$ must be constrained in some way. Kratzer (1998) identifies the problem for a certain. Developping and modifying Hintikka's (1986) analysis, based on scope, she proposes that (a) a certain only has a specific inter- 
pretation and (b) the choice function for a certain has an additional argument which allows for the relativization of choice functions to individuals.

For instance, Hintikka's (1986) example (33) receives the representation in (33'). The value of $f$ must be a function which, given an individual (a value for $x$ ) and the set of dates DATE, picks out a date. So, it is a relativized choice function.

Each husband had forgotten a certain date-his wife's birthday (Hintikka's (1986) example (3))

$$
\forall x(x \text { is a husband } \Rightarrow x \text { had forgotten } f(x, \text { DATE }))
$$

How do we determine the connection between the individual and $f$ ? According to Kratzer, the value of $f$ is contextually determined. For (33), $f$ must pick $x$ 's wife birthday from DATE. Similarly, in a question like Is Richard dating a certain woman? (Kratzer's example (11)), a likely anchor (the value of $x$ ) is the speaker and the choice function "picks out a woman that the speaker has in mind" (Kratzer 1998:169). Using a version of Kratzer's proposal for French UC would create a problem similar to that inherent to Allaert's approach. It is not enough to say that the choice function is contextually determined. For instance, $(29 \mathrm{~b})$ would be associated with the logical form in (29b').

$$
f(x, \text { COLLEAGUE }) \text { accepted to read over my paper }
$$

Following the spirit of Kratzer's proposal, one might say that $f$ picks out a colleague that the speaker has in mind. Now, the speaker has certainly in mind one of the colleagues who accepted to read over the paper. However, this is not the natural interpretation of (29b). One cannot just think of a colleague who helped her for a paper and utter (29b). That is why the perception of the sentence is blurred for some speakers. The following dialogue goes in the same direction.

$$
\begin{aligned}
& \text { A - Qui a révisé ton article? 'Who revised your paper?' } \\
& B-\# \text { Un certain collègue 'A certain colleague' }
\end{aligned}
$$

B's answer may sound uncooperative. If UC simply signalled that the speaker has a certain colleague in mind, the answer should be as neutral as with a standard indefinite ( $u$ n ' $a$ ') under the specific interpretation. So, we have to explain more precisely what is the contribution of UC.

\subsection{The epistemic value of UC}

In fact, in (29b) and (34), the speaker communicates that (i) she is able to identify her colleague and (ii) she knows of another identification by an epistemic agent, who is not necessarily the speaker herself. The latter identification may be provided in the sentence (see (30a)) or be covert (see (30b), (29b), (34)). In the latter case, it is up to the reader to reconstruct the reasons why the speaker signals the second identification, hence variations in the perception of sentences (Hintikka makes a convergent remark about proper names with a certain). Ignoring momentarily the 
case of abstract nouns, we formulate the constraint on UC in (35). For simplicity, we stick to the ordinary conception of i.s. as sets of models.

(35) Let $S$ be a sentence with a tripartite structure [UC] $[\bar{N}][P]$, where $\overline{\mathrm{N}}$ refers to a physical entity. It is appropriate only under an interpretation (i.s.) $s$ such that

(i) the speaker knows which entity satisfies the proper 1-type $\{\overline{\mathrm{N}}(x) \& P(x)\}$ in $s$ and

(ii) for some agent $a$, i.s. $s^{\prime}$ and proper 1-type $\Psi(x)$, (a) the speaker knows that $a$ knows which entity satisfies $\Psi(x)$ in $s^{\prime}$, (b) the speaker knows that this entity is the same as the one that satisfies $\{\overline{\mathrm{N}}(x) \& P(x)\}$, (c) $a \neq$ speaker or $s \neq s^{\prime}$.

Definition (35) captures the fact that the two identifications are independent, via subcondition (iic). Either the speaker has in mind an identification by another agent ( $a \neq$ speaker), or she has in mind another identification $\left(s \neq s^{\prime}\right)$ by herself. In (30a) the speaker identifies the diplomat as the person whom she met, and in (31a) as the person she heard of through John. In addition, she mentions respectively other persons and John as agents who know the diplomat independently. In (36), if $a$ is the speaker, then, at utterance time the speaker may identify the person in question as the person whom she met, and identify her independently as the person whom nobody knew at the party.

J'ai rencontré une certaine personne qu' aucun invité ne connaissait (description of a party)

'I met a certain person whom no guest knew'

Next, UC is used to form certain expressions that have no clear connection with constraint (35), see also (31b) above.

a. Jean a tourné à un certain endroit 'John turned at a certain place'

b. Il y a un lac à un certain endroit 'There is a lake at a certain point'

c. Il a renoncé à combattre, d'une certaine manière 'He abandoned the fight, somewhat'

In view of their frequency in corpora and their non sensitivity to modal cantexts, these expressions are probably collocations. However, they might be partially explained considering that spatio-temporal landmarks (places, moments, etc.) are likely to be known independently from the events they host. E.g., (37b) implies that the lake is at a specific place identifiable independently from its presence. 


\section{The problem(s) of abstract nouns}

In this section, we look at differences linked with the varying nature of the nouns the items under considerations combine with. More precisely, we address the problems raised by the combination with abstract nouns such as tristesse 'sadness', étonnement 'surprise' or temps 'time'. UQ1 exhibits no special behaviour ${ }^{6}$, as it requires non-identification as usual, cf. (38), and we will ignore it in the remainder.

a. J'ai éprouvé un étonnement ?? quelconque devant ce spectacle 'I felt some surprise at this scene'

b. Jean a bien dû éprouver un étonnement quelconque devant ce spectacle 'Still, John must have felt some surprise at this scene'

On the contrary, quelque waives its demand for a context ensuring non-identification with qualities (39a), and UC no longer presupposes identification $(39 b, c)$.

a. J'ai éprouvé quelque étonnement devant ce spectacle 'I felt some surprise at this scene'

b. Jean a dû éprouver un certain étonnement devant ce spectacle 'John must have felt some surprise at this scene'

c. La séparation des particules prend un certain temps, dont personne n'a aucune idée

'Particle splitting takes some time, about which nobody has any idea'

We address two problems in turn: that of the semantic contribution of UC with abstract nouns and that of the variations of quelque with the same nouns.

\subsection{UC and abstract nouns}

Traditionally, the denotational domain of mass nouns contains no individuals. Discontinuity is brought in by the combination with UC, but its mode depends on the type of the N (Tovena 2001). UC's cooccurrence with expressions such as même (even) and en tout cas (anyway) works as a test to tease apart two modes. Roughly speaking, a sentence pair of the form P, (et) même P' signals that $\mathrm{P}^{\prime}$ is a stronger reason to believe some proposition $p$ than $\mathrm{P}$ (see Anscombre 1973, Kay 1997 chap. 2). E.g., in (40a), the possibility that John is a genius is a reason to believe that John might solve a very complex problem that even an intelligent person, normally, would not be able to solve. The en tous cas test is symmetric: $\mathrm{P}$, en tout cas $\mathrm{P}$ ' signals that $\mathrm{P}^{\prime}$ is weaker than $\mathrm{P}$ (Jayez \& Rossari 1999).

a. Jean est intelligent, peut-être même génial 'John is intelligent; he might even be a genius'

b. Jean est génial, en tout cas très intelligent 'John is a genius, very intelligent anyway' 
With quantity-denoting nouns, configuration (41) shows that un certain suggests that the quantity is noticeable. For instance, (41b) is strange because the speaker signals in the first sentence that the process in question takes a noticeable time, in the second sentence that it takes time and that the proposition denoted by the second sentence is stronger than the proposition denoted by the first.

(41) a. Ça prend du temps, et même un certain temps 'It takes time, in fact it will take quite a while'

b. Ça prend un certain temps, et même ?? du temps 'It takes quite a while, it even takes time'

c. Ça prend du temps, en tout cas \# un certain temps 'It takes time, anyway it takes quite a while'

d. Ça prend un certain temps, en tout cas ?? du temps 'It takes quite a while, it takes time anyway'

With quality-denoting nouns, configuration (42) shows that UC suggests that the type of the quality (viz. surprise) is determined. Intuitively, (42a) is odd because the second clause signals that the speaker felt a certain type of surprise. Using UC or a certain to relativize the truth of a sentence to a type is generally perceived as a form of downplaying because it implies that other types do not satisfy the property expressed by the sentence, see (42e).

a. J'ai éprouvé de la surprise, et même une certaine ?? surprise 'I was surprised, I was even surprised in some way'

b. J'ai éprouvé une certaine surprise, et même ?? de la suprise 'I was surprised in some way, in fact I was surprised'

c. J'ai éprouvé de la surprise, en tout cas une certaine surprise 'I was surprised, at least in some way'

d. J'ai éprouvé une certaine surprise, en tous cas ?? de la surprise 'I was surprised in some way, I was suprised anyway'

e. This program solves equations, ?? even / at least equations of a certain type

Following (Bosveld-de Smet 1997), we assume that the existential pronoun $d u / d e$ la signals an overlap relation betwen two entities. We assign to the determiner $d u$ the form (43a). ${ }^{7}$ It says that any object that satisfies the generalized quantifier and any total amount of the substance of type $P$ must overlap. So $d u$ temps refers to any object which is a part of (the total amount of) time. For mass nouns, we assign (43b) to UC. It says that any object that satisfies the generalized quantifier must be a type or amount of $P$ possibly identified by some agent. For quantities, the prefrred mode of identification is by degree/amount $(P-$ amount $)$, whereas identification by type is preferred for qualitites $(P-$ type).
a. $\mathbf{d u}_{\text {exist }}=\lambda P, Q . \exists x(P(x) \& Q(x) \& \forall y($ total-amount $P(y) \Rightarrow$ overlap $(x, y)))$.
b. un certain mass $=$ $\lambda P, Q . \exists x(\diamond[\exists a(a$ knows which $x)] \& P$-type $/ P$ - amount $(x) \& Q(x))$. 
Then, the contribution of un certain is to say that the overlap corresponds to a determinate amount/type of $P$, i.e. an amount/type that an agent might identify. For instance, for (41a) and (42c), we get the following readings: 'It takes time, one can even say it takes a noticeable amount of time' and 'I felt surprise, a certain type of surprise at least'.

\subsection{Quelque and abstract nouns}

Our approach provides a solution also to the unexpected contrasts in (44), where all nouns are compatible with un certain but abstract mass nouns that mention physical dispositions or qualities of objects, situations or behaviours, appear not to be compatible with quelque, unlike nouns denoting psychological states, cf. (39a).

a. Le jeu de ce pianiste souffre de ?? quelque lenteur 'The playing of this pianist suffers from some (occasional) slowness'

b. Le jeu de ce pianiste souffre d'une certaine lenteur 'The playing of this pianist suffers from a certain slowness'

c. Le paysage que je voyais par la fenêtre recelait ?? quelque beauté 'The landscape I was looking at through the window had some beauty in it'

d. Le paysage que je voyais à travers la fenêtre recelait une certaine beauté 'The landscape I was looking at through the window had a certain.beauty'

NPs in (44) are akin to tropes (Campbell 1990, Macdonald 1998), i.e. particular manifestations of abstract properties. Elaborating on Tovena's (to appear) proposal that complements of quelque denote entities that lack individuality, we divide tropes into external and original ones. Both are individuals, as shown by their incompatibility with standard indefinites, cf. (45).
a. ??An intelligence of John
b. ?? A color of my car

However, while external tropes are directly observed, original tropes are the reconstructed causes of external manifestations. They are manifestations of some quality whose exact nature may be abduced in several possible ways. Thereby, they make room for indetermination. In French, many original tropes are noms de sentiment (Anscombre 1995 among others) like amour 'love', frayeur 'fear', exaspération 'exasperation', dédain 'contempt', agacement 'irritation', satisfaction 'satisfaction', désespoir 'despair', confiance 'confidence', jalousie 'jealousy', etc., which are compatible with quelque and un certain. E.g., Jean a montré quelque impatience 'John showed some impatience' means that John had a certain (public) behaviour which points to 'some' (indeterminate) impatience. In contrast, nouns like lenteur 'slowness', beauté 'beauty', souplesse 'litheness', élégance 'elegance', etc. are better with UC. Additional evidence that nouns for external tropes denote observable behaviour comes from the fact that these nouns are not felicitous as complements of suggérer 'to suggest', in contrast with nouns for original tropes. 
a. Ce que je vois suggère beaucoup de frayeur

'What I see suggests much fear'

b. Ce que je vois suggère ?? beaucoup d'élégance [intended sense: physical elegance]

'What I see suggests much elegance'

\section{Conclusion}

We have presented a set of epistemic items that exploit the possibility/impossibility of identifying the referent of the NP.' Two main findings emerged from this investigation. First, the epistemic sensitivity of the items cannot be reduced to "knowledge of the speaker". In addition to the complication introduced by perpectives, there is the fact that UC invokes a scenario structure of "previous acquaintance" which may involve several agents. Second, the link between ignorance and indifference and the combination with abstract nouns show that the basic epistemic value is an element of a more complex network of constraints. The behaviour of the semantically cognate FCI with respect to "indiscriminativity" (see Horn 2000 for just any, Jayez \& Tovena 2001 for $n$ 'importe quel) indicates that the epistemic profile, the scales of relevance and importance and the type of the head noun interact in various ways and that the relation between determiners and (un)certainty is multidimensional.

\section{Endnotes}

[1] More precisely, cancellation occurs only in such cases as the result of discourse revision, signalled, for instance, by special discourse markers like in fact: John met some of the girls conversationally implicates that John did not meet all the girls. One can cancel this implicature by adding in fact he met them all.

[2] UQ1 can also specify the subject: Avec ce nouveau logiciel, un texte (quelconque) peut être scanné 'With this new software, a text (any text) can be scanned'. Some speakers accept even the emphatic form Un texte QUELCONQUE peut être scanné ('ANY text can be scanned'), without any restrictive adjunct.

[3] We ignore the relation between worlds $\left(w, w^{\prime}\right)$ and situations $s$ for simplicity.

[4] We do not claim that n'importe quel or any are not exception-tolerant, that is that the mediating property of IS-generics coincides with the restriction when these items specify the subject. The empirical data are not clear enough to support or falsify such a claim.

[5] The adjective certain 'sure' is intuitively related to the determiners, like quelconque with respect to UQ1 and UQ2. However, the sense of the determiners using certain cannot be described as compositionally involving the sense of the adjective.

[6] Its indifference value may have certain effects, though.

[7] For simplicity, we ignore the special treatment that Bosveld-de Smet proposes for specifier-determiner pairs and we recast her analysis into the standard format for determiners. 


\section{References}

ACHARD-BAYLE, Guy. 2001. Grammaire des métamorphoses. Bruxelles: Duculot.

AllaERT, François. 1999. Certains, certain, un certain: des déterminants de la distinction. Mémoire de DEA, University of Lille III.

Aloni, Maria. 2001. Quantification under Conceptual Covers. Ph.D. dissertation, Amsterdam, ILLC.

Anscombre, Jean-Claude. 1973. Même le roi de France est sage. Communications 20, 40-82.

ANSCOMBRE, Jean-Claude. 1995. Morphologie et représentation événementielle: le cas des noms de sentiment et d'attitude. Langue Française 105, 40-54.

Booth, Wayne C. 1983. The Rhetoric of Fiction. Chicago: he University of Chicago Press, 2nd edition.

Bosveld-DE SMET, Léonie. 1997. On Mass and Plural Quantification. The Case of French des/du-NPs. Ph.D. dissertation, Groningen, ILLC.

CAMPBELl, Keith. 1990. Abstract Particulars. Oxford: Blackwell Publishers.

CARLSON, Gregory N. \& Pelletier, Francis Jeffry (eds). 1995. The Generic Book. Chicago: The University of Chicago Press.

DEKKER, Paul. 1998. Speaker's reference, description and information structure. Journal of Semantics 15, 305-334.

DowTY, David. 1979. Word Meaning and Montague Grammar. Dordrecht: Reidel.

FAGIN, Ronald et al. 1995. Reasoning about Knowledge. Cambridge: MIT Press.

FARKAS, Donka. (this volume)

VON FINTEL, Kai. 2000. Whatever. SALT X, 27-39.

GEACH, Paul, T. 1967. Intentional identity. Journal of Philosophy 64, 627-632.

GenetTe, Gérard. 1983. Nouveau discours du récit. Paris: Éditions du Seuil.

Gerbrandy, Jelle. 1998. Bisimulations on Planet Kripke. Ph.D. dissertation, Amsterdam, ILLC.

GERBRANDY, Jelle. 2000. Identity in epistemic semantics. In Cavedon, L. et al. Logic, Language and Computation. Vol. 3. Stanford: CSLI, 147-159

GEURTS, Bart. 1997. Good news about the description theory of names. Journal of Semantics 14, 319-348.

GeURTs, Bart. 1999. Presuppositions and Pronouns. Amsterdam: Elsevier.

GONDRET, Pierre. 1976. Quelques, plusieurs, certains, divers: une étude sémantique. Le Français Moderne 2, 143-152.

GREENBERG, Yael. (this volume)

GRICE, Paul. 1967. Logic and conversation. William James Lectures, Harvard University. Published in P. Cole and J. Morgan, eds, Syntax and Semantics, Vol. 3, New-York, Academic Press, .

Haspelmath, Martin. Indefinite Pronouns. Oxford: Clarendon Press.

HINTIKKA, Jaakko. 1962. Knowledge and Belief. Ithaca: Cornell University Press.

HINTIKKA, Jaakko. 1986. The semantics of a certain. Linguistic Inquiry 17, 331336. 
HodgeS, Wilfrid. 1997. A Shorter Model Theory. Cambridge: Cambridge U.P.

HORN, Laurence R. 2000. Pick a theory, not just any theory. In Horn, Laurence R. and Kato, Yasuhiko (eds), Negation and Polarity. Syntactic and Semantic Perspectives, Oxford: Oxford University Press, 147-192.

JAYEZ, Jacques \& ROSSARI, Corinne. 1999. Pragmatic connectives as predicates. In Saint-Dizier, Patrick (ed.), Predicative Forms in Natural Language and in Lexical Knowledge Bases, Dordrecht: Kluwer, 285-319.

JAYEZ, Jacques \& TOVENA, Lucia M. 2001. Free Choiceness and Non Individuation. ms. ENS-LSH and Université de Lille (submitted), electronic version at pweb.ens-lsh.fr/j.jayez/jt.pdf .

Kadmon, Nirit \& Landman, Fred. 1993. Any. Linguistics and Philosophy 16, 353-422.

KAY, Paul. 1997. Words and the Grammar of Context. Stanford: CSLI Publications.

KRATZER, Angelika. 1998. Scope or pseudoscope? Are there wide-scope indefinites. In Rothstein, Susan (ed.), Events and Grammar, Dordrecht: Kluwer, 163-196.

KRATZER, Angelika. 2001. Indeterminate pronouns. invited talk given at 13th Amsterdam Colloquium.

LANDMAN, Fred. 1992. The progressive. Natural Language Semantics 1, 1-32.

LEWIS, David. 1968. Counterpart theory and quantified modal logic. The Journal of Philosophy 65, 113-126.

LYONS, John. 1977. Semantics. Cambridge: Cambridge University Press.

REINHART, Tanya. 1992. Wh-in-situ: An apparent paradox. 8th Amsertdam Colloquium, 483-491.

REINHART, Tanya. 1997. Quantifier scope: How labor is divided between QR and choice functions. Linguistics and Philosophy 20, 335-397.

VAN RoOY, Robert. 1997. Attitudes and Changing Contexts. Ph.D. dissertation, U. of Stuttgart.

DE SWART, Henriëtte E. 1991. Adverbs of Quantification: A Generalized Quantifier Approach. Ph.D. dissertation, University of Groningen.

TOVENA, Lucia. 2001. Between mass and count. WCCFL 20, 565-578.

TOVENA, Lucia. (to appear). Determiners and weakly discretised domains. Going Romance 2001.

VAN DE VELDE, D. 2000. Les indéfinis comme adjectifs. In Bosveld, Léonie et al. (eds), De l'indétermination à la qualification. Les indéfinis, Arras: „Artois Presse Université, 203-272.

VeTters, Carl. 1996. Temps, aspect et narration. Amsterdam: Rodopi.

ZEEVAT, Henk. 1997. The mechanics of the counterpart relation. In Künne, Wolfgang et al. Direct Reference, Indexicality, and Propositional Attitudes. Stanford: CSLI, 155-184.

ZUCCHI, Sandro. 1999. Incomplete events, intensionality and imperfective aspect. Natural Language Semantics 7, 179-215. 